\title{
Clinical predictors of symptom improvement failure in gastroparesis
}

\section{Waseem Amjad a,b, Iliana Doychevac, Faisal Kamal' , Adnan Malike, Asha Pandua, Muhammad Asim Shabbira, Mirrah Mumtaz', Asra Batoolg, Andrew Ukleja ${ }^{h}$}

Albany Medical Center, NY; Harvard Medical School, Boston, MA; University of Chicago, IL; University of Tennessee, Memphis, TN; Loyola University Medical Center, Chicago, IL; Beth Israel Deaconess Medical Center, Harvard Medical School, Boston, MA, USA

\section{Abstract}

Background The aim of this study was to determine clinical predictors of gastroparesis outcomes.

Methods Between September 30, 2009 and January 31, 2020, we identified patients with gastroparesis diagnosed based on a ${ }^{99 \mathrm{~m}} \mathrm{Tc}$ sulfur-labeled gastric emptying test. The patients who had no symptom improvement at 4 and 12 weeks were considered to have failed to show clinical improvement. Logistic regression was used to compute the association between different factors and clinical outcomes.

Results We identified 320 patients (mean age $47.5 \pm 5.3$ years, $70.3 \%$ female, $71.3 \%$ Whites). Failure of clinical improvement was seen in $34.7 \%$ patients at 4 weeks and $27.5 \%$ at 12 weeks after the gastroparesis diagnosis. At 4 weeks, chronic kidney disease (adjusted odds ratio [aOR] 2.62, 95\% confidence interval [CI] 1.31-5.26; $\mathrm{P}=0.007)$ and body mass index $(\mathrm{BMI})<18.5 \mathrm{~kg} / \mathrm{m}^{2}(\mathrm{aOR} 9.90$, $95 \% \mathrm{CI} 2.98-32.93 ; \mathrm{P}<0.001)$ were associated with a lack of improvement, whereas type 2 diabetes mellitus (T2DM) was associated with better clinical outcomes (aOR 0.50, 95\%CI 0.25-0.99; $\mathrm{P}=0.047$ ). At 12 weeks, subjects who had undergone post-bariatric surgery had no improvement of their gastroparesis symptoms ( $\mathrm{aOR} 2.43,95 \% \mathrm{CI} 1.01-5.82 ; \mathrm{P}=0.047$ ), whereas T2DM was associated with clinical improvement (aOR $0.46,95 \% \mathrm{CI} 0.22-0.95 ; \mathrm{P}=0.035)$. The subgroup analysis showed that $\mathrm{BMI}<18.5 \mathrm{~kg} / \mathrm{m}^{2}$ in non-diabetics and peripheral neuropathy in diabetics were associated with persistent symptoms.

Conclusions Gastroparesis patients with T2DM had significant symptom improvement. A history of bariatric surgery and renal failure were associated with worse clinical improvement. Peripheral neuropathy in diabetics was associated with persistent symptoms.

Keywords Gastroparesis, symptom improvement, clinical outcomes

Ann Gastroenterol 2022; 35 (X): 1-8 anternal Medicine, Albany Medical Center, Albany NY (Waseem Amjad, Asha Pandu, Muhammad Shabbir); ${ }^{\mathrm{C} C l i n i c a l}$ Research, Harvard Medical School, Boston MA (Waseem Amjad); 'Endocrinology and Metabolism, University of Chicago, Chicago IL (Iliana Doycheva); ${ }^{\mathrm{d}}$ Gastroenterology and Hepatology, University of Tennessee, Memphis, TN (Faisal Kamal); e Internal Medicine, Loyola University

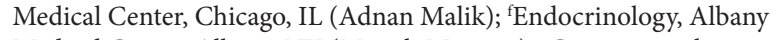
Medical Center, Albany, NY (Mirrah Mumtaz); ${ }^{\mathrm{g}}$ Gastroenterology and Hepatology, Albany Medical Center, Albany, NY (Asra Batool); ${ }^{\mathrm{h}}$ Gastroenterology and Hepatology, Beth Israel Deaconess Medical Center, Harvard Medical School, Boston, MA (Andrew Ukleja), USA

Conflict of Interest: None

Correspondence to: Clinical Investigation, Harvard Medical School, 4 Blackfan Circle, $4^{\text {th }}$ Floor, Boston, MA 02115, USA, e-mail: waseemonline001@gmail.com

Received 26 October 2021; accepted 17 January 2022; published online 14 February 2022

DOI: https://doi.org/10.20524/aog.2022.0696

\section{Introduction}

Gastroparesis (GP) is a complex, debilitating disorder that usually presents with postprandial abdominal pain or fullness, nausea, and vomiting. It is characterized by slow gastric emptying in the absence of mechanical obstruction [1]. It affects only $0.2 \%$ of patients without diabetes mellitus (DM), but its prevalence increases to $5.2 \%$ in those with type $1 \mathrm{DM}$, and is $1 \%$ among patients with type 2 (T2DM) [2]. It is more prevalent in women. GP is largely underdiagnosed because of its nonspecific clinical presentation. The Olmstead community study estimated a GP prevalence of $2 \%$, while the national prevalence is only $0.02 \%$ [3].

GP is a chronic heterogenous disease with persistent symptoms, which contribute to a patient's discomfort and disease burden [4]. To date, studies on the natural history of GP and symptom resolution are scarce. A prospective study based on the National Institute of Diabetes and Digestive and 
Kidney Diseases' Gastroparesis Clinical Research Consortium Gastroparesis Registry has shown that obesity, cigarette smoking, abdominal pain, and gastroesophageal reflux disease (GERD) severity were associated with delayed symptom improvement [5]. The available retrospective studies identified a high baseline Gastroparesis Cardinal Symptom Index (GCSI), idiopathic GP and a history of gastrectomy as predictors of a poor clinical outcome $[6,7]$. Idiopathic GP is more common in young and middle-aged females, but it is not well established whether sex contributes to poor clinical improvement $[8,9]$.

We aimed to estimate the prevalence of refractory GP and to identify the predictors of failure of clinical improvement. We also compared the predictors of failure of clinical improvement among patients with and without diabetes.

\section{Patients and methods}

\section{Study population}

This retrospective cohort study was conducted at a tertiary care hospital in Albany, located in upstate New York, which has a large catchment area. We identified all patients diagnosed with GP between Sept 30, 2009 and January 31, 2020. The follow-up rate was high. The study was approved by the institutional review board of Albany Medical Center, with patient consent waived. We included patients older than 18 years diagnosed with GP based on solid and/or liquid gastric emptying scintigraphy (outpatient and inpatient). Patients were excluded if they were older than 90 years. Cases with incomplete gastric emptying scintigraphy $(n=15)$, evidence of mechanical gastric outlet obstruction $(n=6)$ or peptic ulcer disease $(n=17)$ were also excluded. Patients with GP-like symptoms and a normal gastric emptying study ( $n=518)$ were identified. Of these, 26 had peptic ulcer disease and 47 patients had incomplete data. The baseline date for each patient was set as the day of the first gastric emptying study.

\section{Baseline data and covariates}

GP was defined as delayed gastric emptying of solids and liquids on a scintigraphic gastric emptying study. ${ }^{99 \mathrm{~m}} \mathrm{Tc}$ sulfur colloid-labeled liquid and solid foods were used as test meals. Gastric retention of $\geq 10 \%$ of solids at $4 \mathrm{~h}$ and $\geq 5 \%$ of liquids at $1 \mathrm{~h}$ were defined as delayed gastric emptying. The definition of delayed gastric emptying of liquids at $60 \mathrm{~min}$ was based on the institutional nuclear radiology consensus. In a few cases, both solid and liquid tests were performed within 1-3 days; the date of the first test was recorded. The cases with isolated delayed gastric emptying of liquids only were considered as GP. Severe GP was defined as gastric retention of $>35 \%$ of a test meal after $4 \mathrm{~h}$ for solids and $1 \mathrm{~h}$ for liquids [10]. The control group consisted of patients who presented with GP-like symptoms but had a normal gastric emptying study. Per institutional policy, opiates were stopped at least $48 \mathrm{~h}$ before the study and prokinetics were discontinued at least $72 \mathrm{~h}$ before the study.
DM was defined based on one of the following criteria present before the diagnosis of GP: a) International Classification of Diseases ICD-9 and ICD-10 codes and treated with insulin or oral hypoglycemics for at least 30 days; b) glucose levels $\geq 200 \mathrm{mg} / \mathrm{dL}$ on 2 separate occasions; c) glucose $\geq 200 \mathrm{mg} / \mathrm{dL}$ at least once and treated with oral hypoglycemics or insulin for at least 30 days; and d) glucose levels above $126 \mathrm{mg} / \mathrm{dL}$ on at least 2 separate occasions and treated for at least 30 days [11]. Chronic kidney disease (CKD) was defined as a glomerular filtration rate $<60 \mathrm{~mL} / \mathrm{min} / 1.73 \mathrm{~m}^{2}$ measured on 2 separate occasions [12]. To better understand the effect of weight on clinical outcomes, we created BMI categories following the guidelines of the Centers for Disease Control: a) underweight $<18.5 \mathrm{~kg} / \mathrm{m}^{2}$; b) normal $18.5-24.9 \mathrm{~kg} / \mathrm{m}^{2}$; c) overweight 25 $29.9 \mathrm{~kg} / \mathrm{m}^{2}$; and d) obese $\geq 30 \mathrm{~kg} / \mathrm{m}^{2}$ [13].

Baseline demographic data, including age, sex, race, and comorbidities such as obesity, hypertension, GERD, coronary artery disease (CAD), chronic obstructive pulmonary disease (COPD), history of malignancy and autoimmune disorders, were extracted after careful chart review. Medication use, including proton pump inhibitors (PPI), $\mathrm{H}_{2}$-receptor blockers $\left(\mathrm{H}_{2} \mathrm{RA}\right)$, opiates, antidepressants, prokinetics, oral hypoglycemics, insulin, vitamin supplements, and benzodiazepines were recorded from the medication history at time of the diagnosis or most recent prescription record before the gastric emptying analysis.

\section{Outcomes}

Clinical presentations at baseline, such as nausea, vomiting, abdominal pain, bloating, early satiety, postprandial fullness, constipation, diarrhea, and weight loss, were identified from careful chart review. The patients with no clinical improvement at 4 and 12 weeks were labeled as patients with "failure to improve". Patients with mild or significant improvement were excluded from this group. Our primary outcome was a lack of clinical improvement in GP patients. We also aimed to determine the predictors of failure to show clinical improvement in GP patients. Stratum-specific estimated risk was presented for effect modifiers. The management of GP was based on the American College of Gastroenterology's guidelines [1]. The use of prokinetic medications, dietician consultation, severe GP and gastro-jejunal tube (GJ tube) were identified as effect modifiers in GP patients.

\section{Statistical analysis}

The baseline characteristics were presented as percentages for the categorical variables and as mean \pm standard deviation for continuous variables, and were compared between GP and non-GP patients. A multivariate logistic regression model was used to assess the association of DM and other covariates with a failure of clinical improvement in the GP population during the study period. These models were adjusted for age, sex, race, BMI, DM, GERD, CKD, CAD, COPD, autoimmune disease, cancer, smoking, cirrhosis, neuromuscular disease, opiates, and medical treatment. The calibration and discrimination of 
the model were tested using the goodness-of-fit test and the area under the receiver operating characteristics (ROC) curve, respectively. Overfitting was adjusted in the multivariate model using backward stepwise selection and variables with highly non-significant associations were excluded. We also evaluated the predictors of failure of clinical improvement in diabetics and non-diabetics. All analysis was conducted using STATA17 statistical software. A P-value of $<0.05$ was considered significant.

\section{Results}

\section{Demographics}

During the study period, 1148 patients underwent a gastric emptying study due for suspected GP. Of these patients, 272 were either younger than 18 years or older than 90 and were excluded from further analysis. A further 38 patients were excluded because of an incomplete study, and endoscopic diagnosis of mechanical obstruction, gastric cancer, or peptic ulcer disease. A normal gastric emptying study was noted in 518 patients. The 63 non-GP patients had incomplete data and peptic ulcer disease. A total of $320 \mathrm{GP}$ and 455 non-GP patients were included in the study (Fig. 1).

The mean age of GP patients was $47.4 \pm 16.4$ years, the majority were female (70.3\%) and White (71.3\%). GERD (64.1\%), cigarette smoking (55.3\%), obesity (42.5\%), and DM (40.6\%) were the most common comorbidities in GP patients. Most of the comorbid conditions, including hypertension (39.1\% vs. $31.6 \%)$, DM ( $40.6 \%$ vs. $28.3 \%)$, CKD (18.4\% vs. $8.2 \%)$, CAD ( $15.3 \%$ vs. $5.3 \%)$, COPD (13.4\% vs. $6.2 \%)$, cigarette smoking (55.3\% vs. $47.7 \%)$, and a history of bariatric surgery $(9.1 \%$ vs. $3.3 \%)$, were more prevalent in GP patients than in patients with normal gastric emptying. Of the 29 bariatric surgery patients, 2 had sleeve gastrectomy and the remainder had Roux-en-Y gastric bypass. Patients with GP-like symptoms had a higher prevalence of vitamin B12 deficiency, whereas GP patients were more likely to be vitamin $\mathrm{D}$ - and iron-deficient. PPI, $\mathrm{H}_{2} \mathrm{RA}$, opiates, prokinetics and antidepressants were more commonly used by GP patients (Table 1).

Among GP patients with DM, 66 (52\%) had microvascular complications, including peripheral neuropathy 47 (36.2\%), nephropathy 25 (18.9\%), and retinopathy 19 (15\%).

\section{Failure of clinical improvement}

Patients with delayed gastric emptying had poor clinical outcomes when compared to patients with normal gastric emptying. GP was associated with a higher rate of no clinical improvement at 4 weeks (adjusted odds ratio [aOR] 1.85, 95\% confidence interval $[\mathrm{CI}] 1.31-2.63 ; \mathrm{P}=0.001$ ) compared to patients with a normal gastric emptying study; this difference was not significant at 12 weeks (aOR 1.3, 95\%CI 0.9-1.86; $\mathrm{P}=0.16$ ).

\section{Predictors of no clinical improvement in GP}

At 4 weeks after the diagnosis of GP, CKD (aOR 2.62, 95\%CI 1.31-5.26; $\mathrm{P}=0.007)$ and $\mathrm{BMI}<18.5 \mathrm{~kg} / \mathrm{m}^{2}(\mathrm{aOR} 9.90,95 \% \mathrm{CI}$ 2.98-32.93; $\mathrm{P}<0.001)$ were associated with failure of clinical improvement, whereas T2DM (aOR 0.50, 95\%CI 0.25-0.99; $\mathrm{P}=0.047$ ) was associated with a better outcome (Table 2, Fig. 2). At 12 weeks after the diagnosis of GP, a history of bariatric surgery (aOR 2.43, 95\%CI 1.01-5.82; $\mathrm{P}=0.047$ ) was associated with failure of symptom improvement while T2DM (aOR 0.46, 95\%CI 0.22-0.95; $\mathrm{P}=0.035$ ) had fewer symptom improvement failures (Table 2 and Fig. 3).

The subgroup analysis showed that non-diabetics with BMI $<18.5 \mathrm{~kg} / \mathrm{m}^{2}$ at time of GP diagnosis had failure of clinical improvement at 4 weeks (aOR 21.83, 95\%CI 4.32110.22; $\mathrm{P}<0.001)$ and 12 weeks (aOR 4.06, 95\%CI 1.12-14.76; $\mathrm{P}=0.03$ ) after diagnosis (Supplementary Fig. 1 and 2). Among

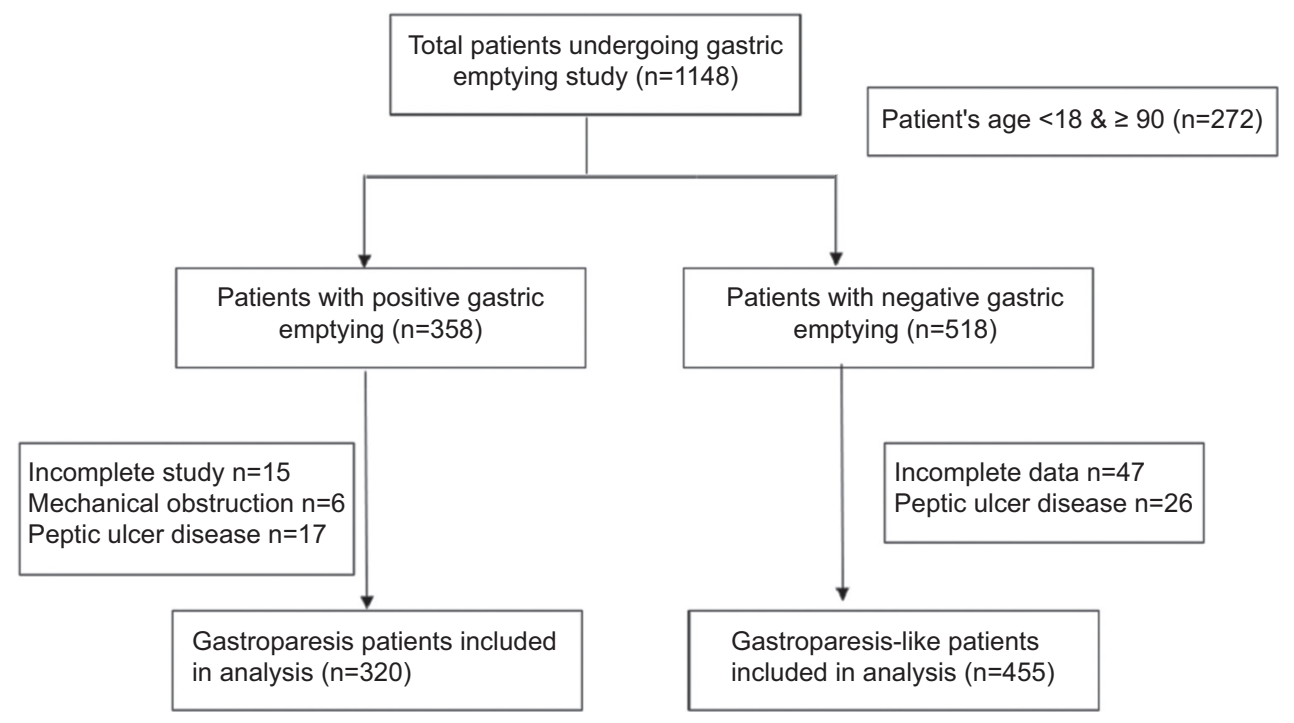

Figure 1 Flowchart showing gastroparesis patient population 
Table 1 Characteristics of all patients (including non-diabetics) and clinical outcomes with univariate effect (P-value)

\begin{tabular}{|c|c|c|c|c|c|}
\hline Variables & Total cases & $\begin{array}{c}\text { Gastric emptying } \\
\text { delayed } \\
(\mathrm{n}=320)\end{array}$ & $\begin{array}{l}\text { Gastric emptying } \\
\text { not delayed } \\
(\mathrm{n}=455)\end{array}$ & $\begin{array}{c}\text { Comparison be- } \\
\text { tween } 2 \text { groups } \\
\text { (P-value) }\end{array}$ & $\begin{array}{c}\text { No recovery } \\
\text { in } 12 \text { weeks } \\
\text { (P-value) }\end{array}$ \\
\hline Age & $46.4 \pm 16.4$ & $47.4 \pm 16.4$ & $45.7 \pm 16.5$ & 0.16 & 0.1 \\
\hline Female sex & 74.3 & 70.3 & 72.7 & 0.46 & 0.75 \\
\hline $\begin{array}{l}\text { Race } \\
\text { White } \\
\text { Black } \\
\text { Other }\end{array}$ & $\begin{array}{c}74.3 \\
17.8 \\
6.6\end{array}$ & $\begin{array}{c}71.3 \\
22.2 \\
6.6\end{array}$ & $\begin{array}{c}76.5 \\
14.7 \\
8.8\end{array}$ & 0.05 & 0.28 \\
\hline \multicolumn{6}{|l|}{ Comorbidities } \\
\hline BMI & $29.3 \pm 8.7$ & $29.3 \pm 8.8$ & $29.3 \pm 8.6$ & 0.90 & 0.25 \\
\hline Hemoglobin A1c (\%) & $7.9 \pm 2.0$ & $8.3 \pm 2.3$ & $7.5 \pm 1.5$ & 0.001 & 0.048 \\
\hline Obesity & 40.6 & 42.5 & 39.3 & 0.38 & 0.39 \\
\hline HTN & 34.7 & 39.1 & 31.6 & 0.03 & 0.34 \\
\hline DM & 33.4 & 40.6 & 28.3 & $<0.001$ & 0.42 \\
\hline T1DM & 7.9 & 11.3 & 5.5 & $<0.001$ & 0.75 \\
\hline T2DM & 26.7 & 29.4 & 22.3 & $<0.001$ & 0.46 \\
\hline GERD & 64.6 & 64.1 & 64.9 & 0.81 & 0.36 \\
\hline CKD & 12.4 & 18.4 & 8.2 & $<0.001$ & 0.005 \\
\hline CAD & 9.4 & 15.3 & 5.3 & $<0.001$ & 0.007 \\
\hline COPD & 9.2 & 13.4 & 6.2 & 0.001 & 0.02 \\
\hline Autoimmune & 11.5 & 10.6 & 12.1 & 0.26 & 0.69 \\
\hline Cancer & 8.8 & 10.3 & 7.7 & 0.2 & 0.19 \\
\hline Neuromuscular $\mathrm{dx}$ & 6.6 & 7.8 & 5.5 & 0.2 & 0.39 \\
\hline Cirrhosis & 2.2 & 2.2 & 2.2 & 0.99 & 0.07 \\
\hline Smoking & 50.8 & 55.3 & 47.7 & 0.04 & 0.03 \\
\hline Bariatric surgery & 5.7 & 9.1 & 3.3 & 0.001 & 0.01 \\
\hline \multicolumn{6}{|l|}{ Micronutrient deficiency } \\
\hline Vitamin D deficiency & 39.84 & 50.0 & 32.7 & $<0.001$ & 0.02 \\
\hline Vitamin B12 deficiency & 13.8 & 12.5 & 14.8 & $<0.001$ & 0.49 \\
\hline Iron deficiency anemia & 37.9 & 50.3 & 29.1 & $<0.001$ & 0.25 \\
\hline \multicolumn{6}{|l|}{ Medications } \\
\hline PPI & 74.9 & 80.9 & 70.7 & 0.001 & 0.6 \\
\hline $\mathrm{H}_{2}$-receptor antagonist & 20.2 & 23.8 & 17.7 & 0.04 & 0.99 \\
\hline Opiates & 29.5 & 41.9 & 20.6 & $<0.001$ & 0.08 \\
\hline Antidepressants & 51.2 & 60.9 & 44.4 & $<0.001$ & 0.13 \\
\hline Prokinetics before diagnosis & 10.5 & 17.5 & 5.5 & $<0.001$ & 0.08 \\
\hline Prokinetic after diagnosis & 27.9 & 52.5 & 10.5 & $<0.001$ & $<0.001$ \\
\hline Oral hypoglycemics & 17.2 & 19.4 & 15.7 & 0.18 & 0.01 \\
\hline Insulin & 23.0 & 31.9 & 16.8 & $<0.001$ & 0.99 \\
\hline Benzodiazepines & 32.3 & 35.4 & 30 & 0.13 & 0.8 \\
\hline \multicolumn{6}{|l|}{ Outcomes } \\
\hline No recovery (week 12) & 23.0 & 27.5 & 19.8 & 0.01 & 0.01 \\
\hline Mortality rate & 9.5 & 14.4 & 6.2 & $<0.001$ & $<0.001$ \\
\hline GJ tube & 5.5 & 11.6 & 1.3 & $<0.001$ & $<0.001$ \\
\hline
\end{tabular}

HTN, hypertension; BMI, body mass index; DM, diabetes mellitus; T1DM, type 1 diabetes mellitus; T2DM, type 2 diabetes mellitus; GERD, gastroesophageal reflux disease; CKD, chronic kidney disease; CAD, coronary artery disease; COPD, chronic obstructive pulmonary disease; GJ, tube gastro-jejunal tube

patients with DM, the presence of peripheral neuropathy was associated with failure of clinical improvement at 12 weeks after GP diagnosis (aOR 3.21, 95\%CI 1.02-10.03; $\mathrm{P}=0.045$ ). The association between DM duration and persistent symptoms was not statistically significant at 4 weeks (aOR 1.05, 95\%CI 1.0-1.11; $\mathrm{P}=0.06$ ) or at 12 weeks (aOR 1.04, 95\%CI 0.98-1.11; $\mathrm{P}=0.16$ ). Glycemic control based on hemoglobin A1c levels also showed no association.

\section{Discrimination}

The ROC curve was generated to measure the discrimination made by the logistic regression model at 4 weeks and 12 weeks. The ROC plots true positive rates on the y-axis vs. false positive rates on the $\mathrm{x}$-axis for every classification threshold. The area under the ROC curve for the no clinical improvement prediction model was 0.73 (95\%CI $0.67-0.80)$ at 4 weeks and 0.71 (95\%CI 0.63-0.78) at 12 weeks (Fig. 4). 
Table 2 Predictors of no clinical improvement in gastroparesis at 4 and 12 weeks

\begin{tabular}{|c|c|c|c|c|}
\hline Variables & $\begin{array}{c}\text { No improvement } \\
\text { at } 4 \text { weeks } \\
\text { Odds ratio }(95 \% \mathrm{CI})\end{array}$ & P-value & $\begin{array}{c}\text { No improvement } \\
\text { at } 12 \text { weeks } \\
\text { Odds ratio }(95 \% \mathrm{CI})\end{array}$ & P-value \\
\hline Age & $1.01(0.99-1.02)$ & 0.34 & $1.0(0.98-1.02)$ & 0.63 \\
\hline Female sex & $1.15(0.64-2.07)$ & 0.65 & $0.79(0.43-1.43)$ & 0.43 \\
\hline White race & $0.99(0.62-1.61)$ & 0.99 & $1.44(0.88-2.36)$ & 0.14 \\
\hline $\mathrm{BMI}<18.5 \mathrm{~kg} / \mathrm{m}^{2}$ & $9.90(2.98-32.93)$ & $<0.001$ & $2.59(0.89-7.56)$ & 0.08 \\
\hline BMI $25-29.9 \mathrm{~kg} / \mathrm{m}^{2}$ & $1.59(0.77-3.28)$ & 0.21 & $1.18(0.57-2.45)$ & 0.66 \\
\hline $\mathrm{BMI} \geq 30 \mathrm{~kg} / \mathrm{m}^{2}$ & $1.30(0.63-2.66)$ & 0.47 & $0.98(0.47-2.03)$ & 0.96 \\
\hline $\begin{array}{l}\text { History of gastric } \\
\text { bypass surgery }\end{array}$ & $2.32(0.96-5.61)$ & 0.06 & $2.43(1.01-5.82)$ & 0.047 \\
\hline T1DM & $0.95(0.41-2.24)$ & 0.91 & $0.39(0.14-1.05)$ & 0.06 \\
\hline T2DM & $0.50(0.25-0.99)$ & 0.047 & $0.46(0.22-0.95)$ & 0.035 \\
\hline CKD & $2.62(1.31-5.26)$ & 0.007 & $1.68(0.80-3.50)$ & 0.17 \\
\hline GERD & $0.74(0.43-1.27)$ & 0.27 & $0.94(0.54-1.64)$ & 0.83 \\
\hline CAD & $1.56(0.73-3.31)$ & 0.25 & $1.61(0.74-3.50)$ & 0.23 \\
\hline Cigarette smoking & $0.85(0.51-1.42)$ & 0.54 & $1.53(0.90-2.63)$ & 0.12 \\
\hline Opiate use & $1.16(0.68-1.98)$ & 0.60 & $0.91(0.52-1.59)$ & 0.74 \\
\hline Antidepressants & $1.10(0.65-1.89)$ & 0.72 & $1.32(0.76-2.31)$ & 0.33 \\
\hline $\begin{array}{l}\text { Autoimmune } \\
\text { disease }\end{array}$ & $1.15(0.50-2.63)$ & 0.75 & $0.73(0.30-1.82)$ & 0.50 \\
\hline $\begin{array}{l}\text { Neuromuscular } \\
\text { disease }\end{array}$ & $0.76(0.27-2.17)$ & 0.61 & $1.14(0.40-3.22)$ & 0.81 \\
\hline
\end{tabular}

BMI, body mass index; T1DM, type 1 diabetes mellitus; T2DM, type 2 diabetes mellitus; GERD, gastroesophageal reflux disease; CKD, chronic kidney disease; CAD, coronary artery disease; COPD, chronic obstructive pulmonary disease

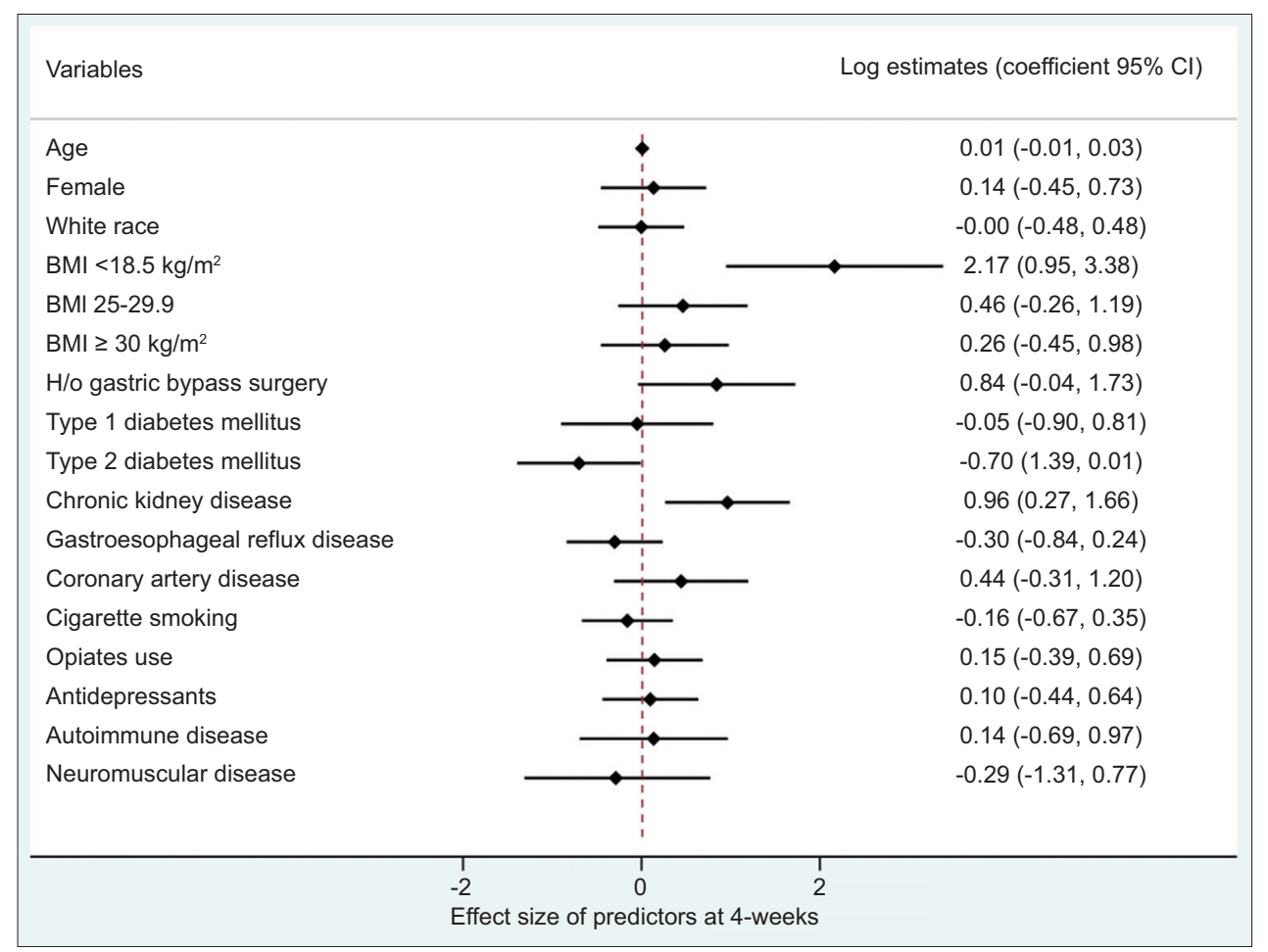

Figure 2 Forest plot of predictors of no clinical improvement at 4 weeks after diagnosis of gastroparesis BMI, body mass index 


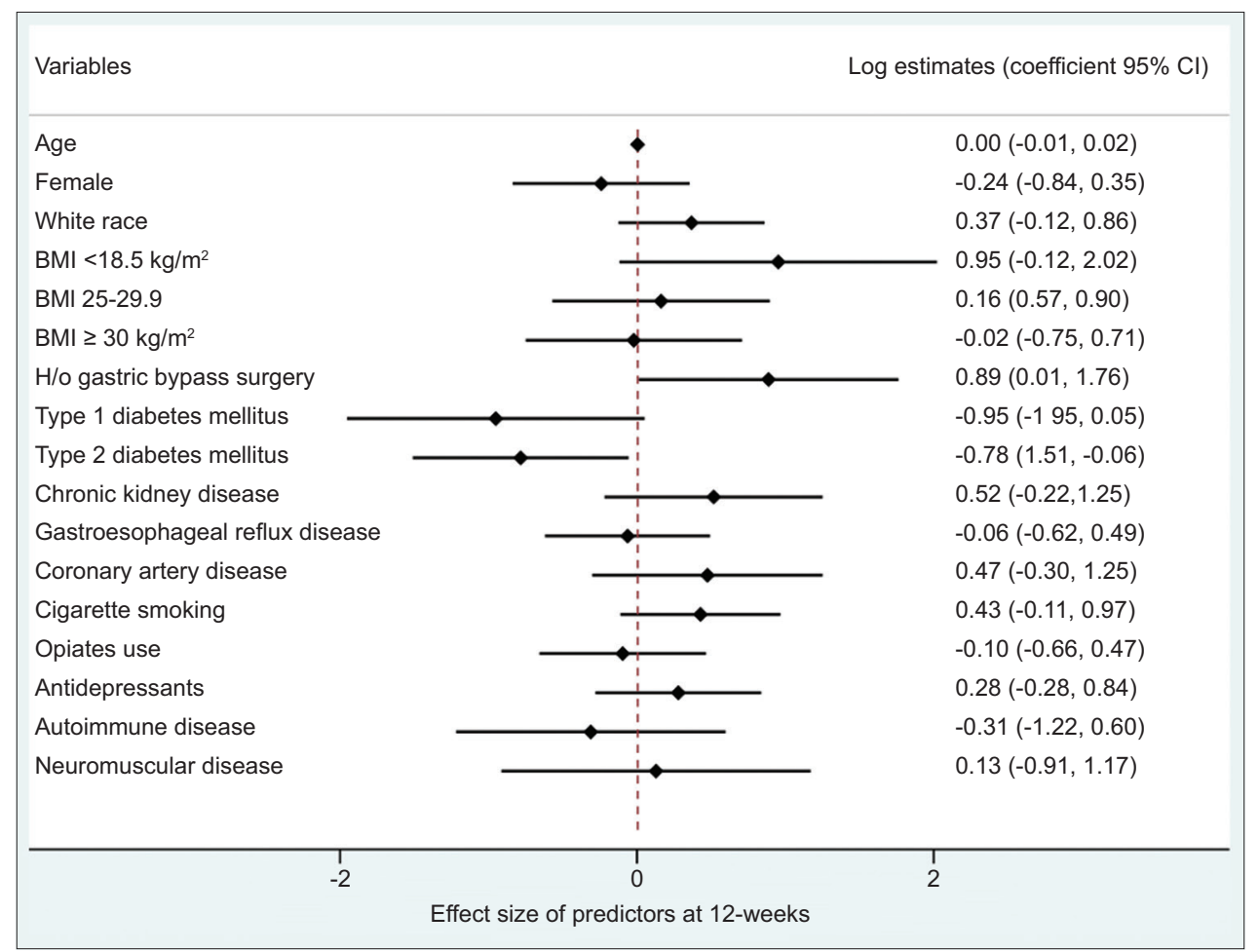

Figure 3 Forest plot of predictors of no clinical improvement at 12 weeks after diagnosis of gastroparesis BMI, body mass index

\section{Therapeutic intervention}

A total of $62(19.4 \%)$ patients had consulted a dietician. Prokinetics were given to $168(52.5 \%)$ patients after the diagnosis of GP, of whom 142 (44.4\%) received metoclopramide, 14 (4.4\%) erythromycin and 12 (3.8\%) both. The advice on diet modification was documented in 211 (65.9\%). Enteral feeding via gastrojejunal tube was provided in 37 (11.6\%) GP patients.

\section{Effect modification}

The risk of failure of symptom improvement at 4 weeks and 12 weeks was greater in patients who had severe GP at the time of diagnosis (OR 2.07, 95\% CI 1.29-3.33; $\mathrm{P}=0.003$, and $\mathrm{OR} 2.01$, 95\%CI 1.22-3.32; $\mathrm{P}=0.006$, respectively). This risk was also higher in patients who used prokinetics (OR 2.21, 95\%CI 1.383.55; $\mathrm{P}=0.001$ and $\mathrm{OR} 2.33$, 95\%CI $1.40-3.90 ; \mathrm{P}=0.001)$ and in those who had a gastrojejunal tube (OR 4.80, 95\%CI 2.309.99; $\mathrm{P}<0.001$ and $\mathrm{OR} 3.29,95 \% \mathrm{CI} 1.63-6.62 ; \mathrm{P}=0.001)$. All individuals who underwent dietician evaluation had persistent symptoms at 4 weeks (OR 3.64, 95\%CI 1.87-7.10; $\mathrm{P}<0.001$ ).

\section{Middle-aged female outcomes}

Our GP cohort had high proportion of middle-aged females (40-65 years): 104 (32.5\%) of the total. Our data did not show high mortality in middle-aged females compared to the rest females of

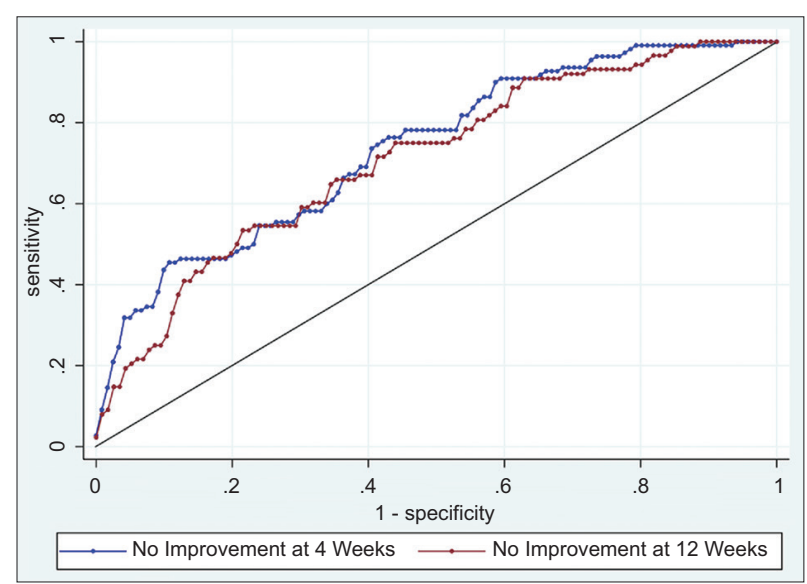

Figure 4 Receiver operating characteristic curves of logistic prediction models for no clinical improvement at 4 and 12 weeks

other ages (aOR 0.54, 95\% CI 0.16-1.86; $\mathrm{P}=0.33$ ) and all other patients (aOR 0.94, 95\%CI 0.37-2.42; $\mathrm{P}=0.90$ ). Similarly, the lack of clinical improvement rate was similar in middle aged women as compared to the rest of the GP population at 4 weeks (aOR $0.72,95 \% \mathrm{CI} 0.37$ $1.41 ; \mathrm{P}=0.34$ ) and 12 weeks ( $\mathrm{aOR} 0.72,95 \% \mathrm{CI} 0.36-1.44 ; \mathrm{P}=0.35$ ).

\section{Discussion}

In this retrospective study evaluating the clinical outcomes of GP, we found that GP patients with T2DM had better symptom 
improvement as compared to non-diabetics. Furthermore, a history of bariatric surgery was associated with no clinical improvement at 4 or 12 weeks, whereas lower BMI and CKD were associated with refractory symptoms at 4 weeks after GP diagnosis. In a subgroup analysis, diabetic peripheral neuropathy was associated with refractory GP at both weeks 4 and 12. The duration of DM in this group was marginally associated with failure of symptom improvement 12 weeks after the diagnosis of GP, whereas a low BMI remained a predictor of poor outcome in non-diabetic GP at 4 and 12 weeks. Prokinetic medications and gastrojejunal tube feeding were used in patients with severe disease, and as a result these patients had persistent symptoms at weeks 4 and 12. Additionally, glycemic control at the time of diagnosis did not predict the clinical outcome.

The study population was predominantly female, as previously reported $[7,14]$. A large number of patients were obese. This could be due to a nationwide increase in obesity prevalence [15]. Obesity is a risk factor for GERD, which explains the latter's high incidence in our patient population [16]. The relation of GERD with GP is multifactorial. The delayed gastric motility causes an increase in acid secretion, gastric volume and the gastroesophageal pressure gradient. The gastric distention can also cause relaxation of a lower esophageal sphincter, which can contribute to esophageal reflux $[17,18]$. Although obesity and GERD were more prevalent in our patients, they did not contribute to the poor clinical outcomes. However, our study showed that a lower-than-normal BMI was associated with poor symptom control. It is possible that the patients with lower BMI had more severe symptoms, including early satiety, vomiting and poor oral intake, which lead to the persistence of symptoms and contribute to malnutrition. As a result, this population has worse clinical outcomes [19].

Our study was unable to reproduce the predictors of a poor outcome, including obesity, smoking and depression, established by a previous prospective large multicenter study over a longer period [5]. This could be due to the duration of follow up or to the heterogeneous and complex nature of GP. Our study further strengthens the expectation of limited improvement in patients with a history of gastric surgery and the subclass of idiopathic GP [7]. The Olmstead County study showed that CKD was associated with high mortality; however, the effect of CKD on the clinical response was not studied [14]. One small study has shown decreased gastric motility in a male population with chronic renal failure. However, there was no association with upper gastrointestinal symptoms [20]. The exact cause of poor gastric motility in CKD is not known; possible mechanisms could be autonomic dysfunction in the setting of uremia, and increased levels of cholecystokinin and gastric inhibitory polypeptide due to poor excretion. These hormones are known to slow down gastric secretions and motility $[21,22]$.

Previous studies that assessed the effect of glycemic control on the severity of GP in patients with DM have shown controversial results [23-25]. To our knowledge, the longitudinal impact of diabetic complications and glycemic control on the clinical outcomes of GP has not been studied. Our study showed that diabetic neuropathy was associated with failure of clinical improvement. A possible explanation is that autonomic neuropathy in GP shares the same mechanism of extrinsic denervation as in peripheral neuropathy. Diabetic patients with GP also have fewer cells of Cajal [26]. Diabetic peripheral neuropathy can be partially reversible with better diabetic control or with pancreas-kidney transplantation [26]. We were unable to establish any correlation between glycemic control and clinical outcomes at 4 or 12 weeks of diagnosis. The effect of DM duration on symptom improvement has not been well studied. Hyett et al [27] showed that patients with diabetic GP diagnosed on the basis of a gastric emptying study had longer duration of DM as compared to patients with GP-like symptoms and a normal gastric emptying study. Although this study showed no difference in healthcare utilization based on the duration of DM, the authors did not examine the effect on symptom improvement.

The strengths of our study include a large sample size, granularity in obtaining patient characteristics, a diverse patient population and complete follow up during the study period. The GP diagnosis was based on a gastric emptying test following the Tougas protocol, unlike older studies that used a less specific protocol, in which $50 \%$ or less gastric emptying at 60 min was considered GP [28]. Overmatching was avoided and those patients with a normal gastric emptying study were not diagnosed as having GP based on subjective information. The calibration and differentiation were good in our prediction models. Our study also had several limitations, which include the retrospective study design and single-center setup. We tried to avoid errors by using 2 reviewers who independently collected data from medical records. It is possible that patients identified with ICD-9 and ICD-10 diagnostic codes were misclassified. This non-differential misclassification might have affected associations away from null. The known and measurable confounders were adjusted, but there may still have been confounding due to unknown or unmeasurable variables, difficult to adjust for in this study design. The non-diabetes GP was not further classified into idiopathic or other etiologies because of the lack of documentation. Long-term data (i.e., more than 12 weeks) were not available because of loss of follow up and the further reduced study population. There were few cases with prior bariatric surgery and statistically significant associations were not seen at 4 weeks. In addition, the subgroup analysis further reduced the observations and a few associations were not statistically significant, although the P-values were marginally high. Therapeutic interventions, including Botox injection, gastric electrical stimulation and gastric peroral pyloromyotomy, were not studied because our center does not perform advanced procedures; Botox injection, in particular, is performed by multiple specialties and the authors were unable to collect these data from chart review. Another limitation was that the symptoms were not scored based on the GCSI or any other severity index, because of the study's retrospective nature. We included symptom presentation and improvement based on patient history.

We concluded that majority of GP symptoms did not improve. Patients without diabetes, BMI $<18.5 \mathrm{~kg} / \mathrm{m}^{2}, \mathrm{CKD}$ or a history of bariatric surgery showed failure of symptom improvement. Among diabetics, peripheral neuropathy and DM duration were associated with poor symptom control. In addition, we found a high prevalence of GERD and obesity in our GP patients. This reflects a general increase in obesity in 
the adult population of the USA. This group may need to be further studied in more detail. We did not find obesity to be a risk factor for poor response to therapy. GP is often associated with weight loss and nutrient deficiencies. The diagnosis of malnutrition may be more challenging in obese individuals with GP. Further well-designed studies are required to confirm these findings, understand the mechanisms, and establish an effective management of refractory GP.

\section{Summary Box}

\section{What is already known:}

- Gastroparesis is a chronic condition associated with refractory symptoms

- The history of idiopathic gastroparesis, gastrectomy, depression and obesity in previous observational studies had shown refractory gastroparesis

- Previous studies had shown a heterogeneous effect of glycemic control on the severity of gastroparesis

\section{What the new findings are:}

- Patients with a low body mass index, chronic kidney disease or a history of bariatric surgery show no symptom improvement at 4 weeks and 12 weeks after gastroparesis diagnosis

- Among diabetics, the duration of diabetes mellitus and a history of diabetic peripheral neuropathy were associated with more refractory disease

- The level of glycemic control had no association with symptom improvement

\section{References}

1. Camilleri M, Parkman HP, Shafi MA, Abell TL, Gerson L; American College of Gastroenterology. Clinical guideline: management of gastroparesis. Am J Gastroenterol 2013;108:18-37.

2. Choung RS, Locke GR $3^{\text {rd }}$, Schleck CD, Zinsmeister AR, Melton LJ $3^{\text {rd }}$, Talley NJ. Risk of gastroparesis in subjects with type 1 and 2 diabetes in the general population. Am J Gastroenterol 2012;107:82-88.

3. Rey E, Choung RS, Schleck CD, Zinsmeister AR, Talley NJ, Locke GR $3^{\text {rd }}$. Prevalence of hidden gastroparesis in the community: the gastroparesis "iceberg". J Neurogastroenterol Motil 2012;18:34-42.

4. Wang YR, Fisher RS, Parkman HP. Gastroparesis-related hospitalizations in the United States: trends, characteristics, and outcomes, 1995-2004. Am J Gastroenterol 2008;103:313322.

5. Pasricha PJ, Yates KP, Nguyen L, et al. Outcomes and factors associated with reduced symptoms in patients with gastroparesis. Gastroenterology 2015;149:1762-1774.

6. Anaparthy R, Pehlivanov N, Grady J, Yimei H, Pasricha PJ. Gastroparesis and gastroparesis-like syndrome: response to therapy and its predictors. Dig Dis Sci 2009;54:1003-1010.
7. Soykan I, Sivri B, Sarosiek I, Kiernan B, McCallum RW. Demography, clinical characteristics, psychological and abuse profiles, treatment, and long-term follow-up of patients with gastroparesis. Dig Dis Sci 1998;43:2398-2404.

8. Parkman HP. Idiopathic gastroparesis. Gastroenterol Clin North Am 2015;44:59-68.

9. Knight LC, Parkman HP, Brown KL, et al. Delayed gastric emptying and decreased antral contractility in normal premenopausal women compared with men. Am J Gastroenterol 1997;92:968-975.

10. Camilleri M. Clinical practice. Diabetic gastroparesis. N Engl J Med 2007;356:820-829.

11. Sacks DB, Arnold M, Bakris GL, et al; Evidence-Based Laboratory Medicine Committee of the American Association for Clinical Chemistry. Guidelines and recommendations for laboratory analysis in the diagnosis and management of diabetes mellitus. Diabetes Care 2011;34:e61-e99.

12. Levey AS, Stevens LA, Schmid CH, et al; CKD-EPI (Chronic Kidney Disease Epidemiology Collaboration). A new equation to estimate glomerular filtration rate. Ann Intern Med 2009;150:604-612.

13. CDC Centers for Disease Control and Prevention. About Adult BMI. Vol 1.; 2020. Available from: https://www.cdc.gov/healthyweight/ assessing/bmi/adult_bmi/index.html [Accessed 3 February 2022].

14. Jung HK, Choung RS, Locke GR $3^{\text {rd }}$, et al. The incidence, prevalence, and outcomes of patients with gastroparesis in Olmsted County, Minnesota, from 1996 to 2006. Gastroenterology 2009;136:1225-1233.

15. Flegal KM, Kruszon-Moran D, Carroll MD, Fryar CD, Ogden CL. Trends in obesity among adults in the United States, 2005 to 2014. JAMA 2016;315:2284-2291.

16. El-Serag $H$. The association between obesity and GERD: a review of the epidemiological evidence. Dig Dis Sci 2008;53:2307-2312.

17. Fass R, McCallum RW, Parkman HP. Treatment challenges in the management of gastroparesis-related GERD. Gastroenterol Hepatol (N Y) 2009;5(10 Suppl 18):4-16.

18. Emerenziani S, Sifrim D. Gastroesophageal reflux and gastric emptying, revisited. Curr Gastroenterol Rep 2005;7:190-195.

19. Parrish CR. Nutritional considerations in the patient with gastroparesis. Gastroenterol Clin North Am 2015;44:83-95.

20. Strid H, Simrén M, Stotzer PO, Abrahamsson H, Björnsson ES. Delay in gastric emptying in patients with chronic renal failure. Scand J Gastroenterol 2004;39:516-520.

21. Dumitrascu DL, Barnert J, Kirschner T, Wienbeck M. Antral emptying of semisolid meal measured by real-time ultrasonography in chronic renal failure. Dig Dis Sci 1995;40:636-644.

22. Owyang C, Miller LJ, DiMagno EP, Brennan LA Jr, Go VL. Gastrointestinal hormone profile in renal insufficiency. Mayo Clin Proc 1979;54:769-773.

23. Reddy S, Ramsubeik K, Vega KJ, Federico J, Palacio C. Do HbA1C levels correlate with delayed gastric emptying in diabetic patients? J Neurogastroenterol Motil 2010;16:414-417.

24. Bytzer P, Talley NJ, Hammer J, Young LJ, Jones MP, Horowitz M. GI symptoms in diabetes mellitus are associated with both poor glycemic control and diabetic complications. Am J Gastroenterol 2002;97:604-611.

25. Bharucha AE, Kudva Y, Basu A, et al. Relationship between glycemic control and gastric emptying in poorly controlled type 2 diabetes. Clin Gastroenterol Hepatol 2015;13:466-476.e1.

26. Camilleri M, Bharucha AE, Farrugia G. Epidemiology, mechanisms, and management of diabetic gastroparesis. Clin Gastroenterol Hepatol 2011;9:5-12.

27. Hyett B, Martinez FJ, Gill BM, et al. Delayed radionucleotide gastric emptying studies predict morbidity in diabetics with symptoms of gastroparesis. Gastroenterology 2009;137:445-452.

28. Tougas G, Eaker EY, Abell TL, et al. Assessment of gastric emptying using a low fat meal: establishment of international control values. Am J Gastroenterol 2000;95:1456-1462. 


\section{Supplementary material}

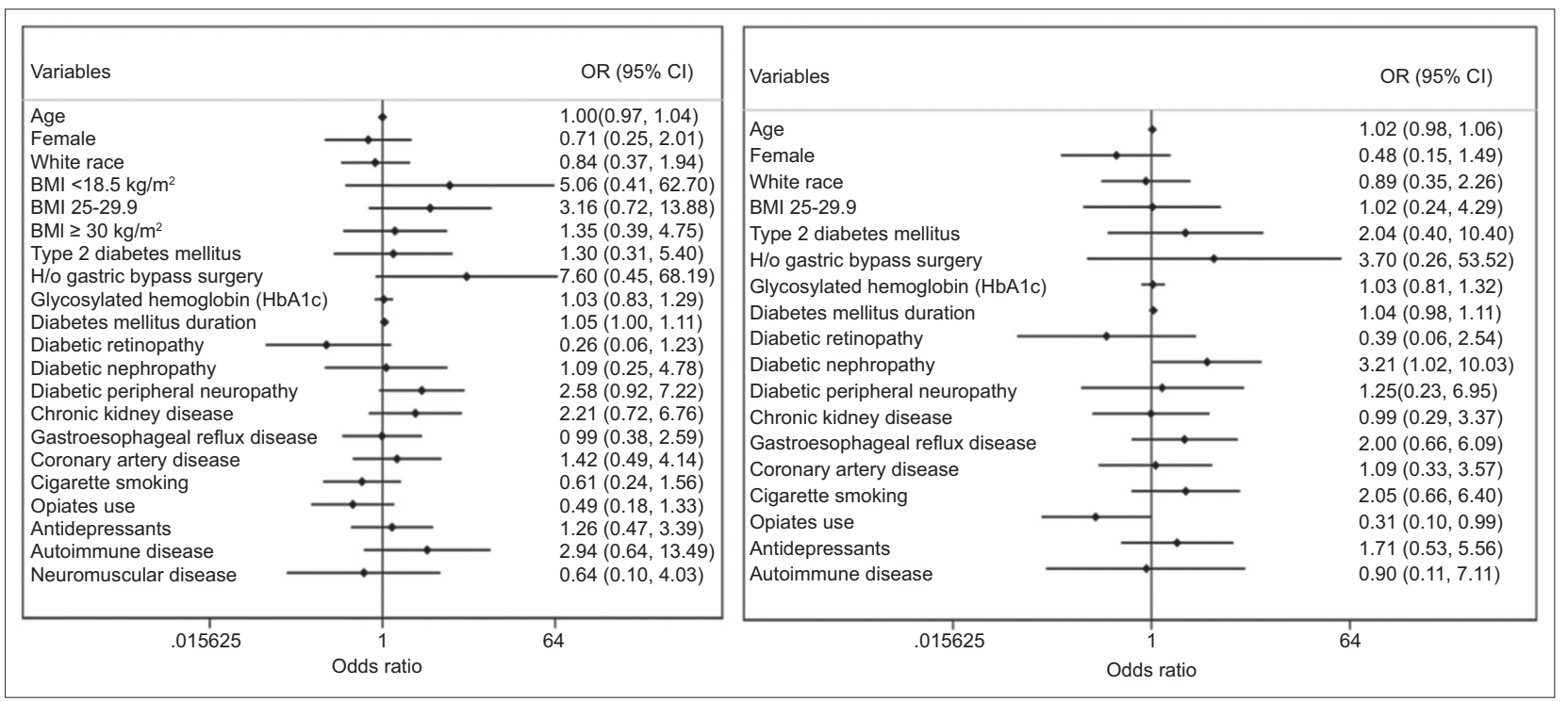

Supplementary Figure 1 (A, B) Predictors of failure of clinical improvement at 4 and 12 weeks after diagnosis of gastroparesis in diabetics $B M I$, body mass index

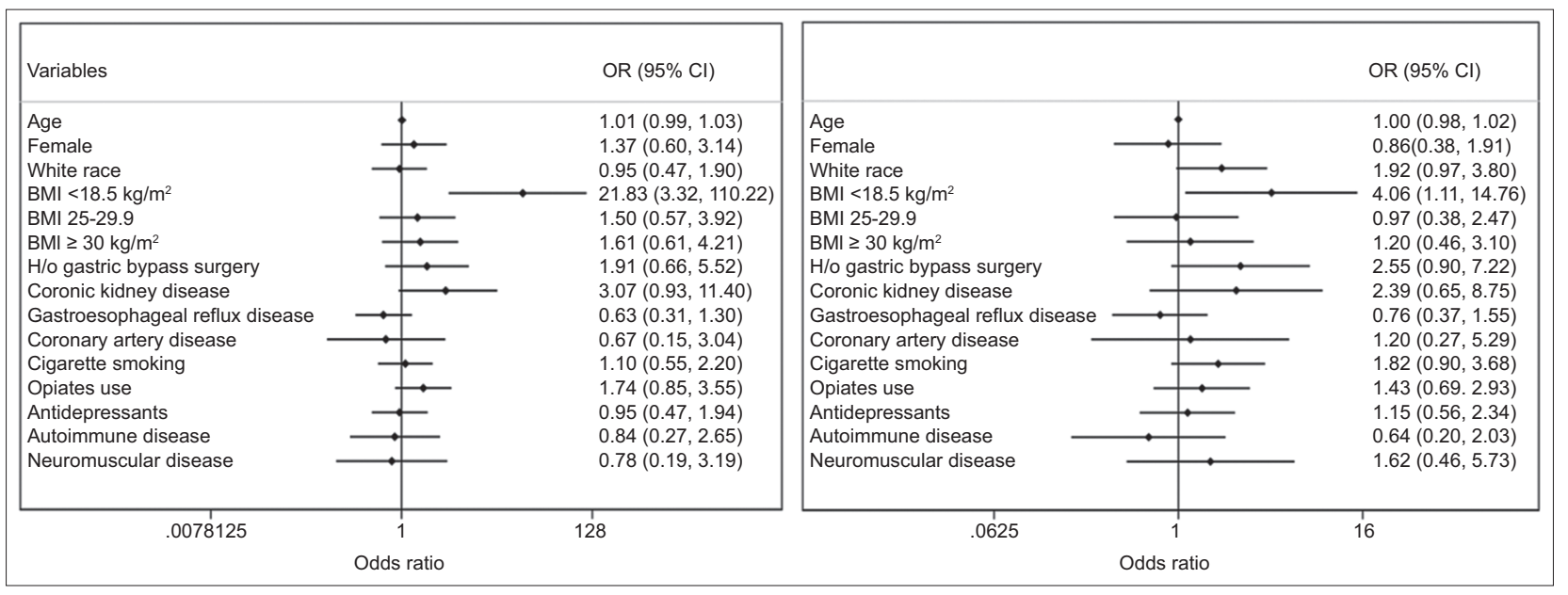

Supplementary Figure 2 (A, B) Predictors of failure of clinical improvement at 4 and 12 weeks after diagnosis of gastroparesis in non-diabetics BMI, body mass index 